\title{
MOTIVOS DE CORTE DE ÁRVORES URBANAS DE CURITIBA NO PERÍODO DE 2013 - 2016
}

\author{
MOTIVES FOR CUTTING TREES IN THE URBAN FOREST OF CURITIBA IN THE \\ PERIOD OF $2013-2016$
}

\begin{abstract}
Dâmaris Araújo da Silva ${ }^{1}$, Daniela Biondi², Antonio Carlos Batista ${ }^{3}$, Alexandre Behling ${ }^{4}$, José Fernando Rios ${ }^{5}$, Allan Rodrigo Nunho dos Reis ${ }^{6}$, Tatiane $\mathrm{Ho}^{7}$
\end{abstract}

\begin{abstract}
RESUMO
A falta de planejamento do espaço urbano tem sido uma das principais causas de corte de árvores. O objetivo deste trabalho foi classificar e analisar os motivos de corte das árvores, no período de 2013 a 2016, dentro da área urbana do município de Curitiba, Paraná. Para isso realizou-se uma análise do levantamento de dados fornecido pela Prefeitura Municipal de Curitiba, sendo a Secretaria Municipal do Meio Ambiente responsável pelas autorizações de corte. No período analisado foram suprimidas 6226 árvores, sendo que os bairros $\mathrm{CIC}$, Boqueirão e Água Verde foram os que apresentaram maior número de árvores cortadas, totalizando 17\%. Tipuana tipu e Ligustrum lucidum foram as espécies mais cortadas, representando $30 \%$ dos cortes. No geral, o conflito locacional foi o principal motivo de corte de árvores nos bairros de Curitiba, representando $64 \%$ do total.
\end{abstract}

Palavras-chave: Planejamento Urbano; Condição de árvores urbanas; Supressão de árvores.

\section{ABSTRACT}

The lack of planning of urban space has been one of the main causes of cut down trees. The objective of this study was to classify and analyze the reasons for cutting trees, from 2013 to 2016, within the urban area of the municipality of Curitiba, Paraná. For this purpose, an analysis of the data provided by the Municipality of Curitiba was carried out, with the Municipal Department of the Environment being responsible for cutting authorizations. In the analyzed period, 6226 trees were suppressed, with the CIC, Boqueirão and Água Verde neighborhoods having the higher number of trees cut, totaling 17\%. Tipuana tipu and Ligustrum lucidum were the most cut species, representing $30 \%$ of the cuts. Overall, the locational conflict was the main reason for cutting trees in the neighborhoods of Curitiba, representing $64 \%$ of the total.

Keywords: Urban planning; Tree condition in urban environments; Trees suppression.

\footnotetext{
Recebido em 11.09.2019 e aceito em 07.05.2020

1 Doutora em Engenheira Florestal. Universidade Federal do Paraná. Curitiba/PR. Email: araujdama@gmail.com

2 Profa. Dra. Engenharia Florestal. Universidade Federal do Paraná. Curitiba/PR. Email: dbiondi@ufpr.br

3 Prof. Dr. Engenharia Florestal. Universidade Federal do Paraná. Curitiba/PR. Email: batistaufpr@gmail.com

4 Prof. Dr. Engenheira Florestal. Universidade Federal do Paraná. Curitiba/PR. Email: alexandre.behling@yahoo.com.br

5 Eng. Agro da Secretaria Municipal de Meio Ambiente de Curitiba. Curitiba/PR. Email: jorios@smma.curitiba.pr.gov.br

6 Mestre em Engenheira Florestal. Universidade Federal do Paraná. Curitiba/PR. Email: allannunho@yahoo.com.br

7 Mestre em Engenheira Florestal. Universidade Federal do Paraná. Curitiba/PR. Email: tatianeho@yahoo.com.br
} 


\section{INTRODUÇÃO}

O meio urbano é marcado por constantes mudanças devido a presença do homem e de seus interesses. A árvore é um dos elementos que sofre pressão frente às alterações humanas, por meio da realização de obras, instalações das redes elétricas, construção de equipamentos urbanos e outros. De modo geral, a necessidade humana tem sido priorizada em relação aos benefícios naturais, como aqueles proporcionados pela floresta urbana (SILVA, 2019).

A arborização urbana é um serviço público e desempenha um papel fundamental para o bem-estar da população (BIONDI; ALTHAUS, 2005). As árvores proporcionam benefícios estéticos, ambientais, sociais e econômicos à medida que contribuem para o embelezamento das cidades, regulação do microclima, filtragem do ar, proteção do solo, redução dos ruídos, melhoria da qualidade do ar, fornecimento de sombra, valoração de imóveis e humanização dos espaços. Além disso, melhorias físicas são perceptíveis à medida que reduz o número de pessoas com doenças respiratórias, bem como a redução do estresse e aumento da qualidade de vida dos habitantes (MOSER; SILVA; HIGUCHI, 2010; OLIVEIRA et al., 2017; SANTOS; LISBOA; CARVALHO, 2012).

Rodrigues et al. (2010), reforçam a importância do reconhecimento da importância da arborização das áreas urbanas pela população, pois a falta de percepção ambiental gera ineficiência nas futuras etapas do planejamento e, consequentemente, no sucesso dos plantios.

Para garantir esses benefícios e manter-se no meio urbano, a árvore precisa apresentar boas condições estruturais e fitossanitárias. Para isso, é necessária a avaliações periódicas sobre as condições das árvores urbanas a fim de deliberar o manejo mais adequado. De acordo com Schallenberger et al. (2010), esse manejo pode envolver desde tratamentos fitossanitários, realização de podas até a necessidade de remoção de árvores.

A medida supressória compõe as práticas de manutenção da arborização, a qual implica na eliminação da árvore por motivos de danos irreparáveis causados por problemas fitossanitários, como por exemplo, doenças, pragas ou presença de erva-de-passarinho; risco de queda ou morte comprovada; a remoção de flores e frutos desagradáveis ou com princípios alérgicos ou ainda a remoção de árvores a pedido da população (BIONDI; ALTHAUS, 2005).

O manejo da arborização urbana é de competência das administrações municipais. Embora haja um protocolo por parte dos órgãos competentes, muitos problemas tem dificultado qual o melhor manejo a ser adotado, devido a falta de técnicos capacitados a fim de orientar um plantio correto, escolha da espécie, melhor formar de conduzir as podas, utilização de tutores, grade de proteção, irrigação em período de estiagem e adubação (RIBEIRO, 2009).

Segundo Bouças (2017), a gestão da arborização de ruas do município de Curitiba, é um dos deveres do Departamento de Arborização Pública Viária da Secretaria Municipal do Meio 
Ambiente (SMMA), órgão vinculado à Prefeitura Municipal de Curitiba, que por meio de vistoria sobre as árvores, conclui sobre a necessidade ou não do corte das árvores. Cuquel; Mielke; Campanholo (2011) em pesquisa sobre o levantamento das autorizações de corte de árvores de Curitiba no período de 2008 a 2009, concluíram que a maioria das solicitações de corte de árvores urbanas não é autorizada; a maioria das autorizações emitidas é para árvores exóticas; as quatro principais espécies autorizadas para corte na rede viária são Ligustrum lucidum (alfeneiro), Acer negundo (acer), Lagerstroemia indica (extremosa) e Ficus benjamina (ficus); e as principais causas de autorização de corte destas quatro espécies são o comprometimento fitossanitário, a morte e danos às edificações.

De modo geral, a análise dos motivos para a solicitação de corte de árvores pelas prefeituras é realizada de maneira subjetiva. Dessa forma, estabelecendo-se uma padronização dos motivos do corte, as vistorias feitas nos locais solicitados pela população serão facilitadas, tornando essa atividade mais prática e rápida.

Considerando a relevância das árvores de ruas para o ser humano e a falta de padronização de informações sobre as diversas causas para a solicitação de corte das árvores pelo órgão responsável pela manutenção da arborização, o objetivo deste trabalho foi classificar e analisar os motivos de corte das árvores no período de 2013 a 2016, dentro do perímetro urbano do município de Curitiba, Paraná.

\section{MATERIAL E MÉTODOS}

\section{Caracterização da área de estudo}

O município de Curitiba está localizado na região sul do Brasil, capital do Estado do Paraná e encontra-se na porção leste do Estado (Figura 1), entre as coordenadas $25^{\circ} 25^{\prime} 40^{\prime \prime S ~ e ~}$ 49¹6'23 "O e faz limite com os municípios de Colombo, Almirante Tamandaré, Campo Magro, Campo Largo, Araucária, Fazenda Rio Grande, São José dos Pinhais e Pinhais (INSTITUTO DE PESQUISA E PLANEJAMENTO URBANO DE CURITIBA (IPPUC), 2016). Administrativamente a cidade possui 75 bairros e 10 regionais (CURITIBA, 2020). 


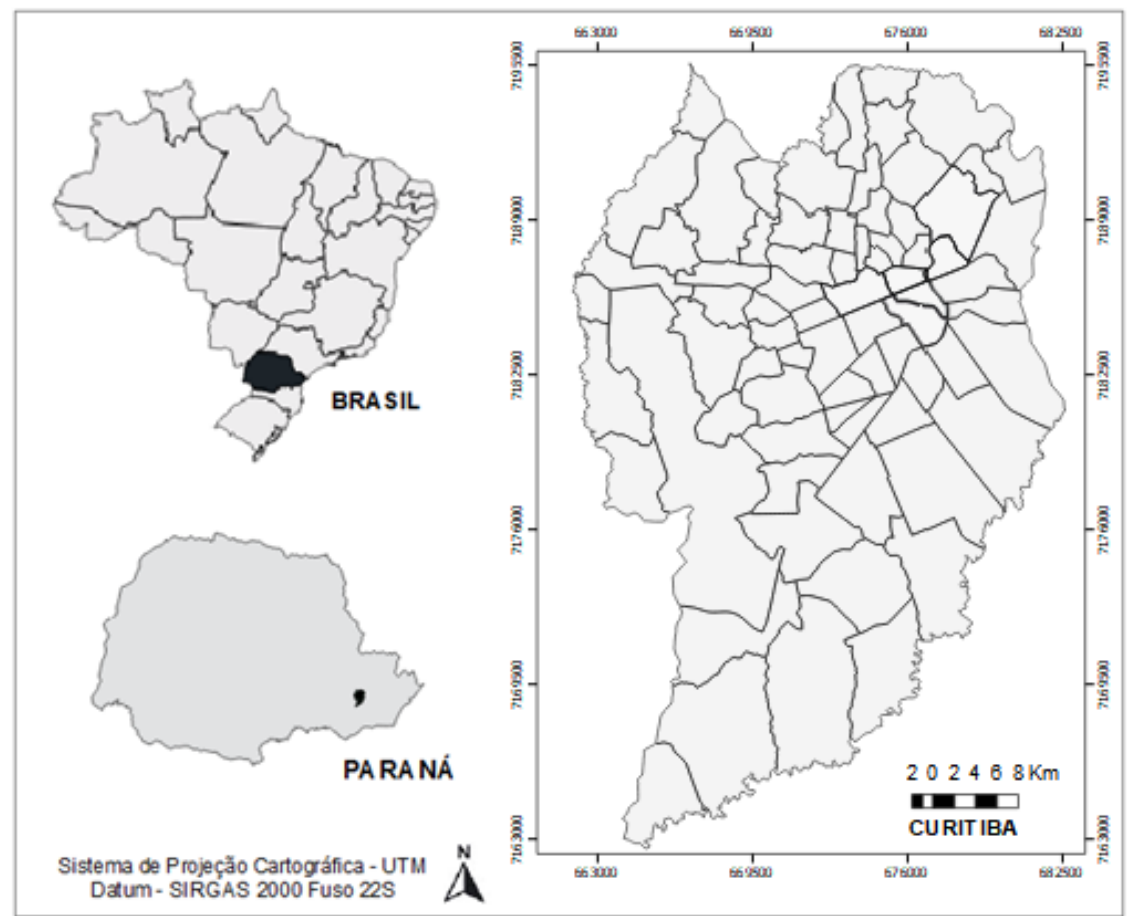

Figura 1. Localização da área de estudo na cidade de Curitiba-PR

Figure 1. Location of the study area in the city of Curitiba-PR

A altitude média de Curitiba é 934 m acima do nível do mar, com uma área de 434,967 $\mathrm{km}^{2}$ e uma população de 1.751.907 habitantes, segundo censo do IBGE para o ano de 2010 (INSTITUTO BRASILEIRO DE GEOGRAFIA E ESTATÍSTICA (IBGE), 2020).

O clima da cidade de Curitiba é do tipo Cfb, conforme a classificação de Köeppen, com temperaturas médias anuais nos meses quentes inferiores a $22{ }^{\circ} \mathrm{C}$ e frios menores que $18{ }^{\circ} \mathrm{C} \mathrm{e}$ média anual de $17{ }^{\circ} \mathrm{C}$. A média anual da umidade relativa do ar fica em torno de $85 \%$ e da precipitação entre 1.300 e 1.500 mm anuais, sem deficiência hídrica ao longo do ano (IPPUC, 2016).

A topografia é ondulada com colinas suavemente arredondadas, dando-lhe uma fisionomia relativamente regular, resultado da existência de uma série de terraços escalonados dispostos em intervalos altimétricos. A geologia é composta por sedimentos da formação Guabirotuba, de origem flúvio-lacustre que preencheram uma antiga e grande depressão, formando a chamada bacia de Curitiba (IPPUC, 2016).

Curitiba está inserida na região fitogeográfica da Floresta Ombrófila Mista que compõe o Bioma da Mata Atlântica, entremeada por pequenos fragmentos de Estepe Gramíneo-Lenhosa (MAACK, 2012).

A floresta urbana de Curitiba, em 2015, foi estimada em 189.826.140,18 $\mathrm{m}^{2}$ (43,69\%) da área total do município (MONTEIRO; BIONDI; ARAKI, 2016). Sabe-se que a cidade possui 1.090 áreas verdes, das quais 455 são praças, 15 bosques, 21 eixos de animação, 2 jardins ambientais, 
470 jardinetes, 56 largos, 30 núcleos ambientais, 24 parques e 15 RPPNMs (IPPUC, 2017). A cidade possui $59,1 \%$ de vias públicas urbanizadas e 76,1\% com arborização viária (CURITIBA, 2020).

De acordo com Monteiro, Biondi e Araki (2016), a cidade de Curitiba apresentou uma floresta urbana cobrindo $43,69 \%$ da cidade, em que 8,98\% corresponde a floresta urbana pública da cidade e $34,70 \%$ corresponde a floresta urbana particular de Curitiba. A área pública representa o arruamento, as áreas verdes e os corpos d'água, os quais totalizaram $109.231 .180,92 \mathrm{~m}^{2}\left(25,14 \%\right.$ da área total da cidade), dos quais $39.028 .589,38 \mathrm{~m}^{2}(8,98 \%$ da área total da cidade) coberto por vegetação.

\section{Procedimentos metodológicos}

Foi feita uma análise dos arquivos da gerência de Arborização do Departamento de Produção Vegetal da Prefeitura Municipal de Curitiba (PMC) no período de 2013-2016, a fim de conhecer as espécies mais solicitadas para o corte.

O processo de corte das árvores de Curitiba é realizado por meio de uma vistoria executada por técnicos do Departamento de Arborização Pública Viária da Secretaria Municipal do Meio Ambiente (SMMA). É necessário o preenchimento do laudo Autorização Ambiental para Remoção de Vegetação, a fim de avaliar as condições estruturais, fitossanitárias e/ou possíveis conflitos locacionais da árvore. A avaliação das árvores consiste nas seguintes variáveis: espécie, porte, localidade em posição em relação à fiação elétrica, condições fitossanitárias e/ou estruturais. Sendo constatada a necessidade da remoção arbórea, a solicitação é deferida e a execução do corte é realizada pelo Departamento de Arborização Pública Viária (BOUÇAS, 2017).

Com as informações fornecidas pela Secretaria Municipal do Meio Ambiente foram classificados os motivos de corte em dois grupos (árvore e ambiente) e oito subgrupos (fitossanitário, estrutural, espécie, estado fisiológico, local, eventos climáticos extremos e solicitações de corte pela sociedade), sendo que as árvores poderiam constar em um ou mais subgrupos de motivos de corte (Figura 2). 


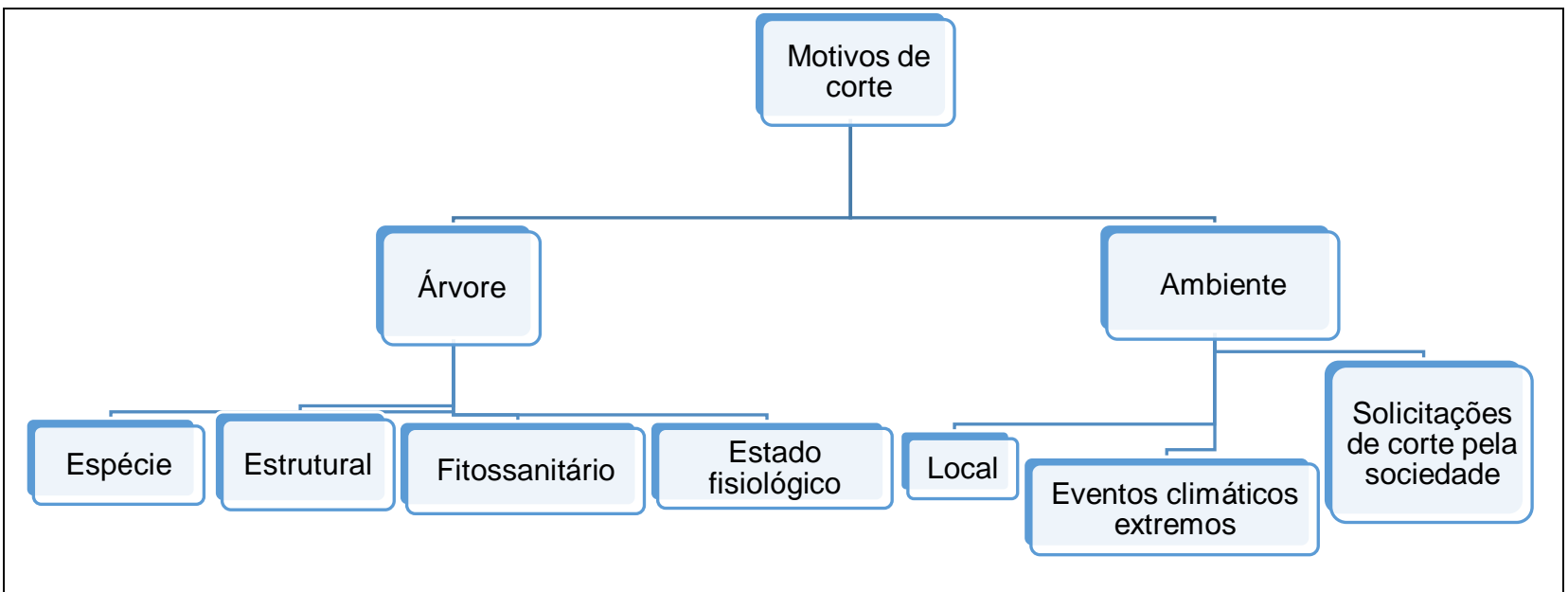

Figura 2. Motivos de corte das árvores de Curitiba no período de 2013-2016

Figure 2. Reasons for cutting trees in Curitiba in the period of 2013-2016 grupo.

$\mathrm{Na}$ Tabela 1 está apresentada a classificação dos motivos detalhados de cada sub-

Tabela 1. Classificação dos motivos de corte das árvores de Curitiba no período de 2013-2016

Table 1. Classification of cutting motives of Curitiba's trees in the period of 2013-2016

\begin{tabular}{|c|c|c|c|c|c|c|}
\hline Espécie & Estrutural & Fitossanitário & $\begin{array}{l}\text { Estado } \\
\text { Fisiológico }\end{array}$ & Local & $\begin{array}{l}\text { Eventos } \\
\text { climáticos } \\
\text { extremos }\end{array}$ & Solicitações \\
\hline Porte & Inclinação & Árvore seca & Velha & $\begin{array}{l}\text { Conflito com a } \\
\text { fiação }\end{array}$ & $\begin{array}{l}\text { Fatores } \\
\text { naturais }\end{array}$ & Corte \\
\hline Sujeira & Rachaduras & Árvore oca & Morta & $\begin{array}{c}\text { Incompatibilidade } \\
\text { local }\end{array}$ & Raio & Avaliação \\
\hline $\begin{array}{l}\text { Árvore faz } \\
\text { sombra }\end{array}$ & Copa disforme & $\begin{array}{c}\text { Árvore } \\
\text { desvitalizada }\end{array}$ & & $\begin{array}{l}\text { Obstrução da } \\
\text { visibilidade }\end{array}$ & Vendaval & Substituição \\
\hline Exótica & $\begin{array}{l}\text { Danos por } \\
\text { colisão de } \\
\text { veiculo }\end{array}$ & Árvores tombadas & & $\begin{array}{c}\text { Realização de } \\
\text { obras }\end{array}$ & & Tratamento \\
\hline Raiz grande & Danos no tronco & Ataque por pragas & & Danos físicos & & Prevenção \\
\hline $\begin{array}{l}\text { Entupimento da } \\
\text { calha }\end{array}$ & Danos na Raiz & Podridão & & Acessibilidade & & Poda \\
\hline $\begin{array}{c}\text { Desrama } \\
\text { natural }\end{array}$ & $\begin{array}{l}\text { Danos } \\
\text { mecânicos }\end{array}$ & Declínio vegetativo & & Danos materiais & & \\
\hline $\begin{array}{c}\text { Galhos altos e } \\
\text { volumosos }\end{array}$ & & $\begin{array}{l}\text { Infestação de erva- } \\
\text { de- passarinho } \\
\text { Estado de } \\
\text { envenenamento } \\
\text { Infiltração }\end{array}$ & & $\begin{array}{c}\text { Insegurança ao } \\
\text { morador } \\
\text { Deslizamento } \\
\text { talude }\end{array}$ & & \\
\hline
\end{tabular}

Dentre os motivos de corte fornecidos pela prefeitura, foram desconsideradas as classes sem motivo de corte e risco de queda, tendo em vista que este se enquadra nas demais classes e não se sabe ao certo o real motivo do corte. Assim, $26 \%$ das árvores suprimidas no período de 2013 a 2016 não apresentaram um motivo justificável de corte.

Para a distribuição dos motivos de corte das árvores no município de Curitiba foi utilizada a variável número de indivíduos cortados por bairro, desenvolvendo-se a partir daí um mapa temático por meio do software QGIS 2.18, conforme método proposto por Pamboukian (2018). 


\section{RESULTADOS E DISCUSSÃO}

Foram suprimidas 6226 árvores nas ruas de Curitiba no período de 2013 a 2016 . Na Tabela 2 estão apresentadas as quinze espécies mais cortadas nesse período, que representam $80 \%$ do total. Dessas, a maioria das espécies (60\%) é de procedência nativa.

Tabela 2. As quinze espécies mais cortadas nas ruas de Curitiba no período de 2013-2016 Table 2. The fifteen most cut species in the streets of Curitiba in the period of 2013-2016

\begin{tabular}{|c|c|c|c|c|}
\hline Espécie & Nome Científico & $\begin{array}{l}\mathrm{N}^{\circ} \text { de } \\
\text { árvores }\end{array}$ & $\%$ & Procedência \\
\hline Tipuana & Tipuana tipu (Benth.) Kuntze. & 950 & 15 & Nativa \\
\hline Alfeneiro & Ligustrum lucidum W.T. Aiton. & 940 & 15 & Exótica \\
\hline Não identificada & - --------- & 803 & 13 & \\
\hline Cinamomo & Melia azedarach L. & 328 & 5 & Exótica \\
\hline Palmeira & Archontophoenix alexandrae H. Wendl. \& Drude & 272 & 4 & Exótica \\
\hline Koeleutéria & Koelreuteria paniculata Laxm. & 271 & 4 & Exótica \\
\hline Ipê & Handroanthus spp. & 261 & 4 & Nativa \\
\hline Dedaleiro & Lafoensia pacari A.St.-Hil. & 228 & 4 & Nativa \\
\hline Araucária & Araucaria angustifolia (Bertol.) Kuntze & 193 & 3 & Nativa \\
\hline Angico & Parapiptadenia rigida (Benth.) Brenan & 181 & 3 & Nativa \\
\hline Acer & Acer negundo $\mathrm{L}$. & 165 & 3 & Exótica \\
\hline Cassia & Cassia sp. & 147 & 2 & Nativa \\
\hline Monjoleiro & Anadenanthera colubrina (Vell.) Brenan & 143 & 2 & Nativa \\
\hline Aroeira & Schinus molle L. & 131 & 2 & Nativa \\
\hline \multirow[t]{2}{*}{ Extremosa } & Lagerstroemia indica $\mathrm{L}$. & 117 & 2 & Exótica \\
\hline & & 5130 & $80 \%$ & \\
\hline
\end{tabular}

Tipuana e alfeneiro foram as espécies mais cortadas nas ruas de Curitiba no período de 2013-2016, representando cerca de 30\% do total das árvores suprimidas. Segundo Biondi e Althaus (2005), a tipuana não deve ser plantada nas ruas devido ao seu porte e, raízes superficiais, levantando as calçadas. Embora essa espécie seja muito utilizada na arborização brasileira, vários autores (BOBROWSKI; BIONDI, 2013; ANDREATTA et al., 2011; SANTOS; LIMA; FERREIRA, 2016), constataram a relação de incompatibilidade da árvore com o local disponível, ocasionando conflito aéreo (copa e fiação) e quebra do calçamento.

Biondi e Althaus (2005) afirmam que desde 1970 o alfeneiro já fazia parte da arborização de Curitiba e foi muito plantada até a década de 80 , mas atualmente não se planta mais nas ruas por diversos motivos, entre eles estão: ser uma espécie exótica-invasora, possuir raízes superficiais que levantam as calçadas e apresentar rápido crescimento, fazendo-a competir e impedir a regeneração de plantas nativas.

Na Figura 3 observa-se a relação entre as árvores cortadas e os seus respectivos motivos de supressão nas ruas de Curitiba-PR no período de 2013 a 2016. 


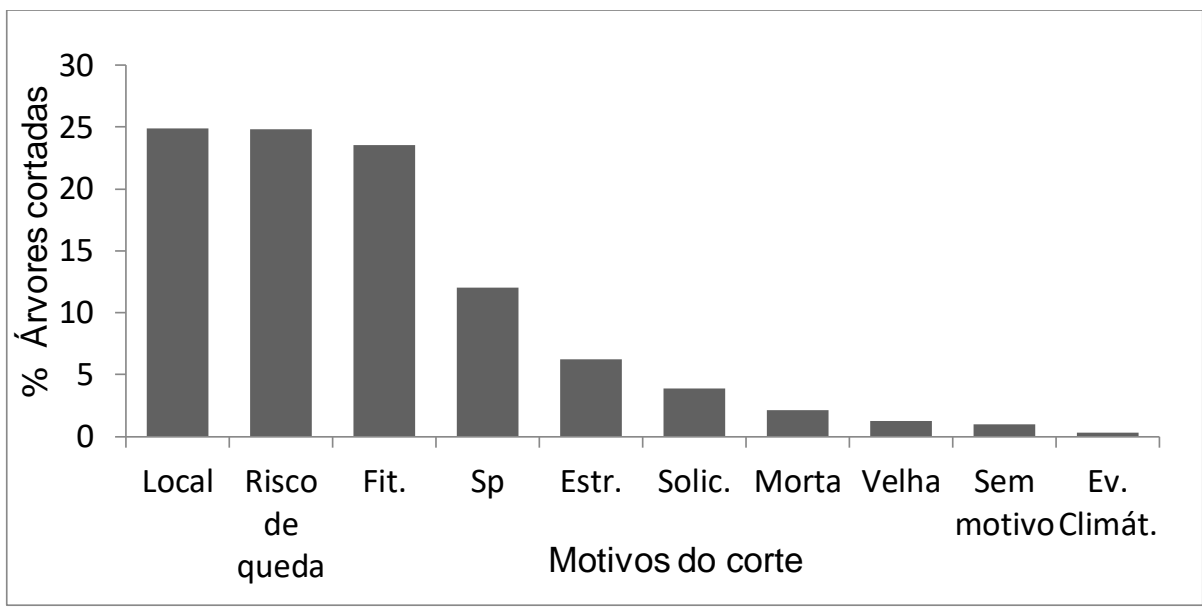

Legenda: Fit: motivos fitossanitários; Sp: motivos da espécie; Estr: motivos estruturais; Solic: solicitação; Ev.climát.: eventos climáticos

Figura 3. Percentagem de árvores cortadas nas ruas de Curitiba-PR e os motivos do corte no período de 2013-2016

Figure 3. Percentage of trees cut on the streets of Curitiba-PR and the reasons for cutting in the period of 2013-2016

Embora o motivo "risco de queda" justifique $25 \%$ do corte das árvores, este é um motivo bem abrangente e pode pertencer aos demais motivos de corte, não sendo possível determinar o real motivo de supressão, por isso foi um motivo desconsiderado. Dessa forma, os principais motivos de corte, cerca de $60 \%$ das árvores, ocorreram devido aos conflitos com o meio-físico, problemas fitossanitários e ligados ao comportamento da espécie.

Esse resultado revela que essas árvores foram plantadas sem conhecimento sobre a espécie e em locais inapropriados para o seu desenvolvimento. Para Barros, Guilherme e Carvalho (2010), o planejamento urbano não inclui o projeto de arborização, possibilitando a ocorrência de plantios irregulares de espécies sem compatibilidade com o ambiente. Essa ação causa sérios prejuízos, como rompimento de cabos de alta-tensão, interrupções no fornecimento de energia elétrica, entupimento em redes de esgoto, obstáculos para circulação e acidentes envolvendo pedestres, veículos ou edificações.

De acordo com Pivetta e Silva Filho (2002) algumas características da espécie devem ser requeridas a fim de evitar possíveis transtornos, entre elas estão: a espécie deve apresentar resistência a pragas e doenças; velocidade de desenvolvimento média para rápida; não deve produzir frutos grandes; os troncos e ramos das árvores devem ter lenho resistentes; não conter princípios tóxicos; apresentar bom efeito estético; as flores devem ser de preferência de tamanho pequeno; não devem exalar odores fortes e nem servirem para vasos ornamentais; a planta deve ser nativa ou, se exótica, deve ser adaptada; a folhagem dever ser de renovação e tamanho favoráveis; a copa das árvores devem ter forma e tamanho adequado e o sistema radicular devem ser profundo. 
Os ataques por pragas e doenças são os principais causadores dos problemas fitossanitários. Para Harris (1992), os danos fitossanitários são causados por fung os, bactérias, vírus, microplasmas, nematódeos e plantas parasitas, podendo levar ao baixo crescimento; necrose de folhas, ramos e frutos; ou até mesmo morte de uma árvore inteira.

Os principais motivos de corte das árvores da cidade de Curitiba no período de 20132016 estão apresentados na Figura 4.

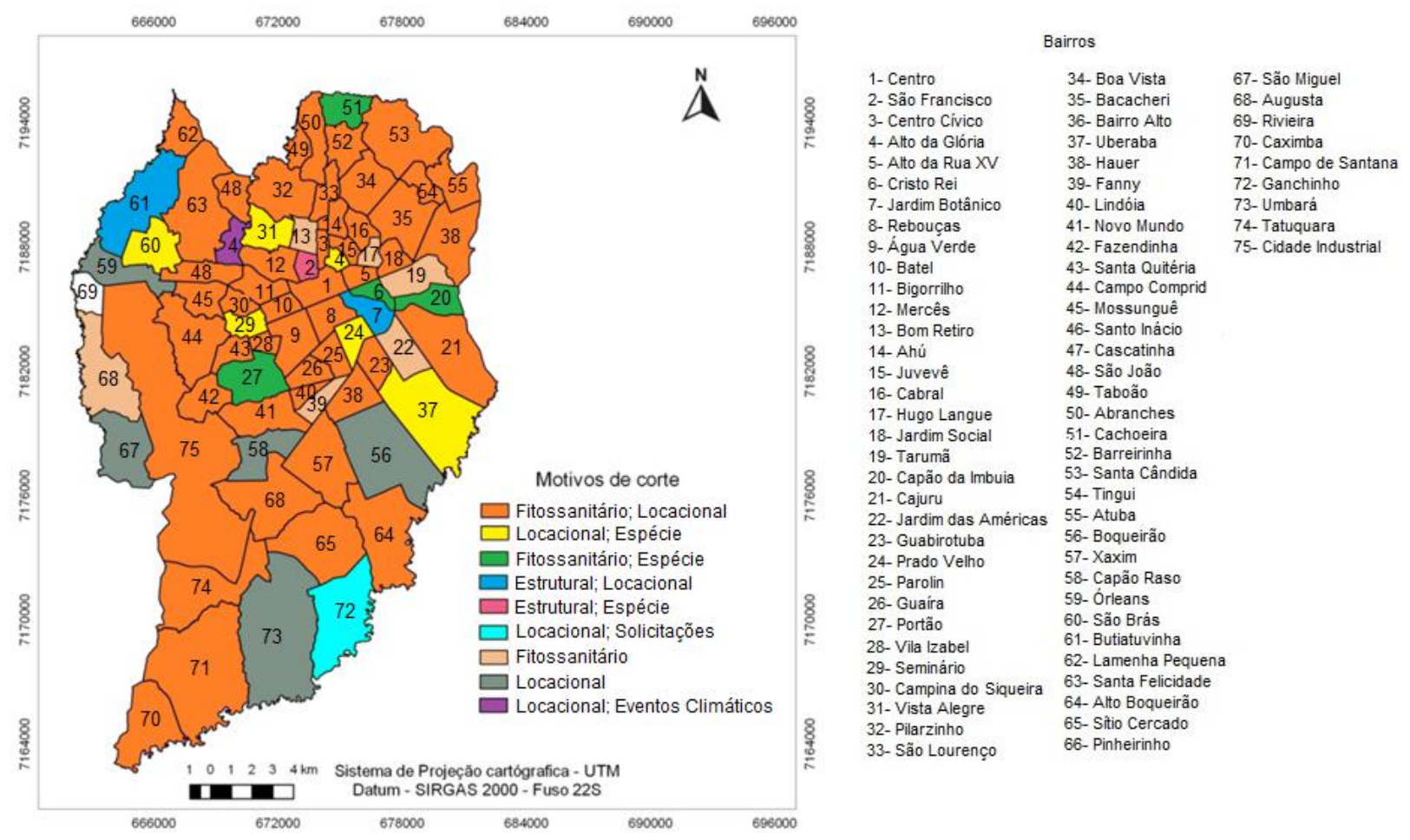

Figura 4. Espacialização dos motivos de corte das árvores de risco da cidade de Curitiba Figure 4. Specialization of the cutting reasons of the risk trees of Curitiba city

Observou-se que o conflito da árvore com o local e os problemas fitossanitários são os principais motivos de corte de árvores nos bairros de Curitiba-PR, representando $64 \%$ do total.

Os bairros CIC, Boqueirão e Água Verde têm como principal justificativa de corte os problemas fitossanitários (22\%) e conflito locacional (51\%), representando $73 \%$. Os bairros Mercês, Cajuru, Sítio Cercado, Portão, Xaxim e Alto Boqueirão, possuem como principal motivo de corte os problemas fitossanitários e conflito locacional (40\%); fitossanitário e espécie (40\%), representando $80 \%$. Os demais bairros apresentam suas justificativas de corte distribuídas em todas as classes apresentados na Figura 4.

Os conflitos das árvores com o meio-físico ocasionam danos tanto para o local como para a árvore, além de elevar os custos pela maior necessidade de corte de árvores adultas. De acordo com o CREA-PR (2016), as árvores tende a enfrentar diversos problemas locais, como: o reduzido espaço para o crescimento tanto das raízes como para a copa; as práticas de podas 
drásticas inadequadas (mutilação da árvore); os danos mecânicos (por veículos, cortadores de grama, anelamento do tronco, e outros); o vandalismo; a compactação do solo; a deficiência de água e nutrientes; as temperaturas modificadas e a poluição do ar.

Mayer, Oliveira Filho e Bobrowski (2015) constataram que para amenizar os conflitos do meio-físico e as árvores, recomenda-se que o gestor da arborização inclua informações de suporte na tomada de decisão, tais como: os dados sobre a altura da rede elétrica, a largura de calçadas, a dimensão de canteiros e a localização precisa da canalização subterrânea. A dificuldade de visualizar a canalização de água e esgoto tem facilitado a obstrução da tubulação pelas das raízes, ocasionando a interrupção no fornecimento de água e contaminação do solo.

Os problemas fitossanitários das árvores são resultantes de práticas de manejo inadequadas, incompatibilidade com meio-físico e suscetibilidade da árvore a pragas e doenças. A poda é uma das práticas que pode reduzir danos causados por vento, ataques de insetos, problemas de doenças e melhorar a arquitetura da copa. A remoção imediata de ramos quebrados ou mortos é um exemplo da prevenção de problemas futuros por meio da poda (CREA-PR, 2016). Bouças (2017) constatou que o comprometimento fitossanitário foi o principal motivo de corte das árvores de ruas na regional Matriz do município de Curitiba-PR em 2017, correspondendo a 50,3\% dos cortes e indicou maior manutenção nas árvores para que os índices de comprometimento fitossanitário sejam atenuados.

\section{CONCLUSÕES}

Foram suprimidas 6.226 árvores da arborização de ruas de Curitiba no período de 2013 a 2016. Neste período, a Tipuana tipu e Ligustrum lucidum foram as espécies mais cortadas nas ruas de Curitiba, representando $30 \%$ do total das árvores suprimidas.

O conflito da árvore com o local e os problemas fitossanitários foram os principais motivos de corte de árvores nos bairros de Curitiba-PR, representando 64\% do total. Os bairros CIC, Boqueirão e Água Verde foram os que apresentaram maior número de árvores cortadas, totalizando $17 \%$, tendo como principal motivo de corte o conflito locacional (73\%).

\section{REFERÊNCIAS}

ANDREATTA, T. R.; BACKES, F. A. A. L.; BELLÉ, R. A.; NEUHAUS, M.; GIRARDI, L. B.; SCHWAB, N. T.; BRANDÃO. B. S. Análise da arborização no contexto urbano de avenidas de Santa Maria, RS. Revista da Sociedade Brasileira de Arborização Urbana, Piracicaba, v. 6, n. 1, p. 36-50, 2011. 
BARROS, E. F. S.; GUILHERME, F. A. G.; CARVALHO, R. S. Arborização urbana em quadras de diferentes padrões construtivos na cidade de Jataí. Revista Árvore, Viçosa, v. 34, n. 2, p. 287-295, 2010.

BOBROWSKI, R.; BIONDI, D. Espécies não tradicionais e espécies indesejáveis na composição da arborização de ruas. Enciclopédia Biosfera, Centro Científico Conhecer- Goiânia, v.9, n.17, p. 1293-1304, 2013.

BIONDI, D.; ALTHAUS, M. Árvores de rua de Curitiba: cultivo e manejo. Curitiba: FUPEF, 2005. 177p.

BOUÇAS, G. C. Análise de supressões na arborização de ruas na Regional Matriz do município de Curitiba - PR. Curitiba, 2017. 59f. Trabalho de conclusão de curso (TCC em Engenharia Florestal) - Universidade Federal do Paraná - UFPR. Curitiba, 2017.

CONSELHO REGIONAL DE ENGENHARIA E AGRONOMIA DO PARANÁ (CREA-PR). Arborização Urbana. Série de Cadernos Técnicos da Agenda Parlamentar, 2016. Disponível em http://www.crea-pr.org.br/ws/wp content/uploads/2016/12/arborizacao-urbana.pdf>. Acesso: 20 out. 2017.

CUQUEL, F.L.; MIELKE, E.C.; CAMPANHOLO, R. Levantamento das autorizações de corte de árvores de Curitiba. Revista Brasileira de Horticultura Ornamental, Campinas, v.17, n.1, p.5762, 2011.

CURITIBA. Prefeitura Municipal. Perfil da cidade de Curitiba. Disponível em: $<$ https://www.curitiba.pr.gov.br/conteudo/perfil-da-cidade-de-curitiba/174>. Acesso em: 05 mai. 2020.

HARRIS, R. W. Arboriculture: integrated management of landscape trees, shrubs, and vines. New Jersey: Prentice-Hall International, 1992. 674p.

INSTITUTO BRASILEIRO DE GEOGRAFIA E ESTATÍSTICA (IBGE). Curitiba/Panorama. Disponível em: <https://cidades.ibge.gov.br/brasil/pr/curitiba/panorama>. Acesso em: 05 mai. 2020.

INSTITUTO DE PESQUISA E PLANEJAMENTO URBANO DE CURITIBA (IPPUC). Curitiba em dados. Curitiba, 2016. Disponível em: <http://curitibaemdados.ippuc/>. Acesso em: 08 fev. 2017.

INSTITUTO DE PESQUISA E PLANEJAMENTO URBANO DE CURITIBA (IPPUC). Desenvolvimento sustentável: indicadores de sustentabilidade de Curitiba - 2017. Curitiba: IPPUC, $77 \mathrm{p}$.

MAACK, R. Geografia física do estado do Paraná. Ponta Grossa: Editora UEPG, 2017. 526 p.

MAYER, C. L. D.; OLIVEIRA FILHO, P. C. de; BOBROWSKI, R. Análise espacial de conflitos da arborização de vias públicas: caso Irati, Paraná. Revista Floresta, Curitiba, v.45, n.1, p.11 - 20, 2015.

MONTEIRO, M. M. G.; BIONDI, D.; ARAKI, H. A floresta urbana da cidade de Curitiba, PR.

Revista Floresta, Curitiba, v. 46, n. 4, p. 425 - 438, 2016. 
MOSER, P.; SILVA, A. C.; HIGUCHI, P. Arborização urbana: um encontro da natureza com o meio urbano. Espiral, São Paulo, v. 42, n.1, p. 1-10, 2010.

OLIVEIRA, V. P.; DIAS, J. G. S.; RIBEIRO, A. T.; OLIVEIRA, L. B. S.; MARIANO, M. O.; PINTO, D. S. A percepção da população sobre arborização em um conjunto habitacional no município de Paragominas-PA. Revista da Sociedade Brasileira de Arborização Urbana. Piracicaba, v.12, n. 3, p. 27-36, 2017.

PAMBOUKIAN, S.V.D. Mapas Temáticos no QGIS. Disponível em: < http://labgeo.mackenzie.br/fileadmin/LABGEO/Curso/03._Aula_03/0304._Mapas_TeTeTeTem_ no_QGIS.pdf>. Acesso: 17 nov. 2018.

PIVETTA, K. F. L.; SILVA FILHO, D. F. Arborização Urbana. Boletim Acadêmico, Série Arborização Urbana. Jaboticabal: UNESP, 2002. 69p.

RIBEIRO, F. A. B. S. Arborização Urbana em Uberlândia: Percepção da População. Revista da Católica, Uberlândia, v. 1, n. 1, p. 224-237, 2009.

RODRIGUES, T. D.; MALAFAIA, G.; QUEIROZ, S. E. E.; RODRIGUES, A. S. L. Percepção sobre arborização urbana de moradores em três áreas de Pires do Rio - Goiás. Revista de Estudos Ambientais, Blumenau, v. 12, n. 2, p. 47-61, 2010.

SANTOS, T. O. B.; LISBOA, C. M. C. A.; CARVALHO, F. G. Análise da arborização viária do bairro de Petrópolis, Natal, RN: uma abordagem para diagnóstico e planejamento da flora urbana. Revista da Sociedade Brasileira de Arborização Urbana, Piracicaba, v. 7, n. 4, p. 90-106, 2012.

SANTOS, F. S.; LIMA, D. P.; FERREIRA, R. M. Levantamento de espécies arbóreas em via urbana do município de Foz do Iguaçu-Paraná. Biota Amazônia, Macapá, v. 6, n. 3, p. 52-54, 2016.

SCHALLENBERGER, L. S.; ARAUJO, A. J. de; ARAUJO, M. N. de; DEINER, L. J. MACHADO, G. O. de. Avaliação da condição de árvores urbanas nos principais parques e praças do município de Irati-PR. Revista da Sociedade Brasileira de Arborização Urbana, Piracicaba, v.5, n.2, p.105-123, 2010.

SILVA, D. A. da. Risco de queda de árvores nas ruas de Curitiba - PR. Curitiba, 2019. $135 f$. Tese (Doutorado em Engenharia Florestal) - Universidade Federal do Paraná - UFPR. Curitiba, 2019. 